\title{
The Impact of Covid-19 on Flight Departure Delay Time and Cancellations at Philadelphia International Airport
}

\author{
Kelvin Yuan ${ }^{1}$ and Brian Vernachio"\# \\ ${ }^{1}$ Cherry Hill High School East, Cherry Hill, NJ, USA \\ \#Advisor
}

\section{ABSTRACT}

The emergence of Covid-19 has deeply disturbed the aviation industry in many aspects. This study examines the effect of Covid-19 on departure delay time and flight cancellation at Philadelphia International Airport (PHL). By analyzing data of nearly 200,000 flights departed from PHL between January 2019 and February 2021, the research found that Covid-19 noticeably reduced flight departure delay time, and flight cancellations sharply rose then quickly dropped. Furthermore, flight departure delay time is highly correlated with the number of flights: the lower the number of flights, the lower the delay time. The ultimate cause is the lack of passengers, as the number of passengers dictates the number of flights an airline can successfully operate.

\section{Introduction}

This paper studies the impact of the Covid-19 pandemic on flight departure delays at Philadelphia International Airport. Flight delays hurt airlines, airports, and passengers, and they have large impacts in many social and economic sectors (Carvalho et al. 2020). Annually, US airlines pay billions of dollars due to flight delays (Ball et al. 2010). In the medical field, organs are transported using commercial aircrafts. Because organs are time-sensitive, it is crucial for airplanes to depart and arrive on time.

The airline industry is one of the largest industries in America today. Airplanes are one of the most efficient forms of transportation, especially for long distances. Each year, hundreds of millions of people throughout America travel by air to both international and domestic destinations. The Bureau of Transportation Statistics reports that in 2019 alone, there were 811 million domestic passengers who flew within the US and 115 million international passengers who flew either to or from the US. However, the recent Covid-19 outbreak has heavily affected the United States. Since January 2020, Covid-19 has quickly spread throughout the United States, causing a nationwide lockdown. People were encouraged to stay indoors and not to expose themselves to the public. As a result, the airline industry suffered in many different aspects as they tried to adjust to the current situation.

There has been much research completed on how Covid-19 affected airline revenues and passenger loss, which will be reviewed in the next section. There has also been research conducted on how airlines have been coping with the pandemic, and predictions on how airlines will emerge after the pandemic. However, the effect of Covid-19 on flight delays has not been extensively quantitatively studied.

\section{Literature Review}

The Covid-19 outbreak has heavily affected airlines all over the world. The International Civil Aviation Organization states that throughout 2020 , there will be a total of 1,878 to 3,227 million passenger losses, along with $\$ 244$ to $\$ 420$ 
billion potential loss of gross operating revenue for the airline industry. Covid-19 has caused the steepest decline in world passengers when compared to other crises such as the Financial Crisis of 2007, the Asian Crisis of 1997, the SARS outbreak, and the Gulf Crisis.

This outbreak forces airlines into an extremely difficult situation, as airlines need to follow newly devised travel restrictions while trying to make as much revenue as possible from the dwindling amount of customers that are still willing to fly during the pandemic. A survey conducted by the International Air Travel Association reported that " $30 \%$ of respondents would wait six months or more before they considered commercial airline travel" and that an additional 10\% "would not travel before a year or more had passed" (Lamb et al. 2020). These numbers suggest that the outbreak not only has an immediate impact on demand but that the effects of the Covid-19 outbreak will leave devastating aftermath as well. The new travel restrictions also come at the expense of the airlines. One measure implemented by airlines around the world to help prevent the spread of Covid-19 among passengers is to keep the middle seats open, which according to studies can cut the chance of getting the virus in half (Barnett 2020). However, by implementing this measure, airlines are losing up to $1 / 3$ of the revenue per flight. There are other measures used to fight Covid-19 as well. Thai Airlines, for example, made sure passengers were at least one meter apart throughout the whole flight (including check-in, boarding, and in-flight), and even wrapped meals in more packaging than usual to prevent the spread of the virus. On certain flights, Thai Airlines also reserved an area of the plane for quarantine, in case anybody displayed symptoms on board (Pongpirul et al. 2020). All these measures cost airlines money, whether directly or indirectly.

During the initial outbreak of the virus, many airlines temporarily shut down operations, such as LOT Polish Airlines, CSA Czech Airlines, and Montenegro Airlines. At one point, a total of eighteen European airlines came to a complete standstill (Budd et al. 2020). In the United States, three airlines went bankrupt due to the pandemic (Pallini 2021). In order to combat the huge loss, airlines have taken extreme measures. For example, British Airways decided to "bring forward its decision to discontinue Boeing 747 fleets as part of its recovery strategy" (Amankwah-Amoah 2020). As a result, the entire fleet of Boeing $747 \mathrm{~s}$ has been retired much earlier than previously planned in order to save money. American Airlines stored up to 435 aircrafts and retired more than 100 aircrafts due to the impact of the virus outbreak (Bailey 2020). Other airlines, such as Emirates, an airline based in the Middle east, decided to implement a " $25-50 \%$ basic salary reduction" (Amankwah-Amoah 2020). In an attempt to alleviate the impact of the virus, governments around the world have given airlines billions of dollars in an attempt to bail them out. With such huge and lasting impacts, the question of whether the commercial aviation industry can ever return back to normal arises. When examining the Chinese domestic aviation market, there is a dramatic difference between the ongoing recovery rate against Covid-19 when compared to the recovery rate against SARS back in 2003. The recovery rate for Covid19 is much slower than that of the SARS outbreak (Suau-Sanchez 2020).

Overall, the pandemic has deeply impacted airlines all around the world, while airlines are trying their best to generate as much revenue as possible despite the lack of passengers. In addition, airports themselves are also losing money. Research shows that "the financial impact on airports is massive and it will take several years to regain what was lost during the COVID-19 standstill period" (Serrano et Kazda 2020). For example, the airport traffic in Europe fell 97\% in March as Covid-19 cases rose to almost five hundred thousand (Forsyth et al. 2020).

Most research about the impact of Covid-19 on the airline industry has focused on revenue and passenger loss. There are virtually no scientific studies on how the Covid-19 outbreak is affecting flight delay times and cancellations, although numerous studies before Covid-19 have investigated factors affecting flight delays. Abdelghany et al. (2004) reported that weather accounts for nearly $75 \%$ of system delays. Asfe et al. (2014) presented an empirical investigation to determine important factors on flight delays. They found that technical defects and delayed entry were among the most important factors to blame for flight delays. Hsu et al. (2007) built models to analyze flight-delay propagation, allowing for behavioral response. Wang et al. (2003) proposed a simple analytic model, which explicitly separates the controllable factors that impact delays and propagation of delays. To fill the research gap, this paper investigates the impact of the Covid-19 pandemic on flight departure delays, using Philadelphia International Airport as the study ground. 


\section{Methods}

In order to study the impact of the Covid-19 outbreak on the departure delay times at Philadelphia International Airport, it is necessary to observe delay times on a wide spectrum of time spanning from the beginning of 2019 (prepandemic) until now. The best suitable method to undertake this research is "Empirical Analysis." Empirical analysis studies quantitative data rather than theories and ideas. In this paper a multitude of quantitative flight data will be reviewed and analyzed in order to draw a conclusion. Basic statistical analysis such as means, frequency counts, and correlations will be applied. The method of collecting data is similar to the one used in Sun et al. (2020), in which the researchers obtained data from a flight database named FlightRadar24. However, in this study, data was gathered from the Bureau of Transportation Statistics (BTS) instead of FlightRadar24. This is because the BTS has easily accessible data starting from 1987, well beyond the parameters of this study. Flightradar24, on the other hand, only has easily accessible data up to a week prior to the day of accessing the database. A general outline which will be elaborated on in the following paragraphs is as listed:

1.) Downloaded flight data from January 2019 to February 2021 (the latest data available as of the time of writing) from the BTS. Flight data includes date, airline, flight number, airline, origin, destination, departure delay time, cancellations, etc. Departure delay time is calculated by subtracting scheduled departure time from actual departure time.

2.) Used a Python script to select flights that departed from Philadelphia International Airport

3.) Used a Python script to compute basic statistics such as the average delay time, the total number of flights, and the total number of cancellations for every month from January 2019 to February 2022. The results were plotted on graphs using R.

4.) Analyzed results of data analysis and drew conclusions.

\section{Step 1}

The first step was to download data from the Bureau of Transportation Statistics. The BTS is a branch of the government that specializes in transportation data, so the data retrieved for this study is credible. The BTS provides downloadable airplane delay data in the form of spreadsheets, organized by months. Every month from January 2019 to February 2021 was taken into account, resulting in a total of 26 spreadsheets. Delay times are shown in the second to the last column of the example below. Negative numbers denote that the airplane left before the scheduled departure time, while positive numbers indicate that the airplane left after the departure time. A zero means that the plane departed on schedule.

\begin{tabular}{|c|c|c|c|c|c|c|c|c|}
\hline $3 / 23 / 20$ & AA & 1933 & PHX & ORD & 1720 & 1713 & -7 & 0 \\
\hline $3 / 23 / 20$ & AA & 1934 & LGA & PHL & 600 & 547 & -13 & 0 \\
\hline $3 / 23 / 20$ & AA & 1937 & CLT & BOS & 2230 & 2212 & -18 & 0 \\
\hline $3 / 23 / 20$ & AA & 1938 & CLT & ORF & 2240 & 2240 & 0 & 0 \\
\hline $3 / 23 / 20$ & AA & 1939 & CLT & $\mathrm{MCO}$ & 1637 & 1631 & -6 & 0 \\
\hline $3 / 23 / 20$ & AA & 1939 & MCO & CLT & 1919 & 1902 & -17 & 0 \\
\hline $3 / 23 / 20$ & AA & 1940 & MEM & DFW & 552 & 544 & -8 & 0 \\
\hline $3 / 23 / 20$ & AA & 1941 & PHL & ORD & 1605 & & & 1 \\
\hline $3 / 23 / 20$ & AA & 1942 & CLT & LGA & 2018 & 2047 & 29 & 0 \\
\hline $3 / 23 / 20$ & AA & 1943 & CLT & MSY & 2021 & 2012 & -9 & 0 \\
\hline $3 / 23 / 20$ & AA & 1945 & LAS & LAX & 813 & 811 & -2 & 0 \\
\hline $3 / 23 / 20$ & AA & 1946 & CLT & RIC & 2040 & & & 1 \\
\hline $3 / 23 / 20$ & AA & 1948 & PHL & PIT & 825 & 821 & -4 & 0 \\
\hline $3 / 23 / 20$ & AA & 1948 & PIT & PHL & 1033 & 1025 & -8 & 0 \\
\hline
\end{tabular}

Example 1. A small portion of data from a spreadsheet downloaded from BTS. Listed in the second to last column on the right are the delay times, with negative times meaning an early departure. The last column shows cancellations, 
with the number 1 meaning that the flight is cancelled. The number of cancellations was tracked for each month during this research process.

\section{Step 2}

A python script was written to extract all flights from "PHL" (i.e., Philadelphia International Airport) from the 26 spreadsheets, resulting in a total of 199,221 flights for analysis. In example 1, the fourth column shows the departure airport. The fifth column, which shows the arrival airport, was ignored, as this paper did not take the destination into account in any aspect.

\section{Step 3}

Due to the high number of flights, computer programming was necessary to analyze the data and compute statistics. Python was used to compute the average delay time, the total number of flights, and the total number of cancellations for every month. The results are plotted using $\mathrm{R}$. The average delay time per month was calculated by adding up all the delay times, both positive and nonpositive, and dividing by the total number of departed flights that month. Cancelled flights were excluded when calculating average delay times.

\section{Step 4}

The final step was to analyze the results from Step 3 and draw conclusions. begin. Some sub-questions to be examined include: Did any year have a drastic result on the chart? Are there any anomalies? What are the trends? Anomalies and trends include, but are not limited to, days that seem to have a much higher or lower delay time than others, or a lot more or less canceled flights. By investigating these questions, the overall research question can then be answered.

\section{Results}

\section{Departure Delay Time}

Table 1 and Figure 1 show the monthly average departure delay time at PHL from January 2019 (19-01) to February 2021 (21-02).

Table 1. Average departure delay time (in minutes) from January 2019 to February 2021.

\begin{tabular}{|l|l|l|l|l|l|l|l|l|l|l|l|l|}
\hline & Jan. & Feb. & Mar. & Apr. & May & Jun. & Jul. & Aug. & Sep. & Oct. & Nov. & Dec. \\
\hline 2019 & 4.7 & 7.6 & 7.2 & 10.4 & 13.8 & 15.0 & 18.1 & 15.9 & 5.3 & 6.2 & 5.5 & 12.6 \\
\hline 2020 & 4.8 & 7.8 & 0.7 & -5.1 & -4.2 & -2.1 & 0.6 & -0.5 & -3.2 & -0.2 & -2.1 & 1.3 \\
\hline 2021 & -0.6 & 1.4 & \multicolumn{10}{|l|}{} \\
\hline
\end{tabular}




\section{average delay time}

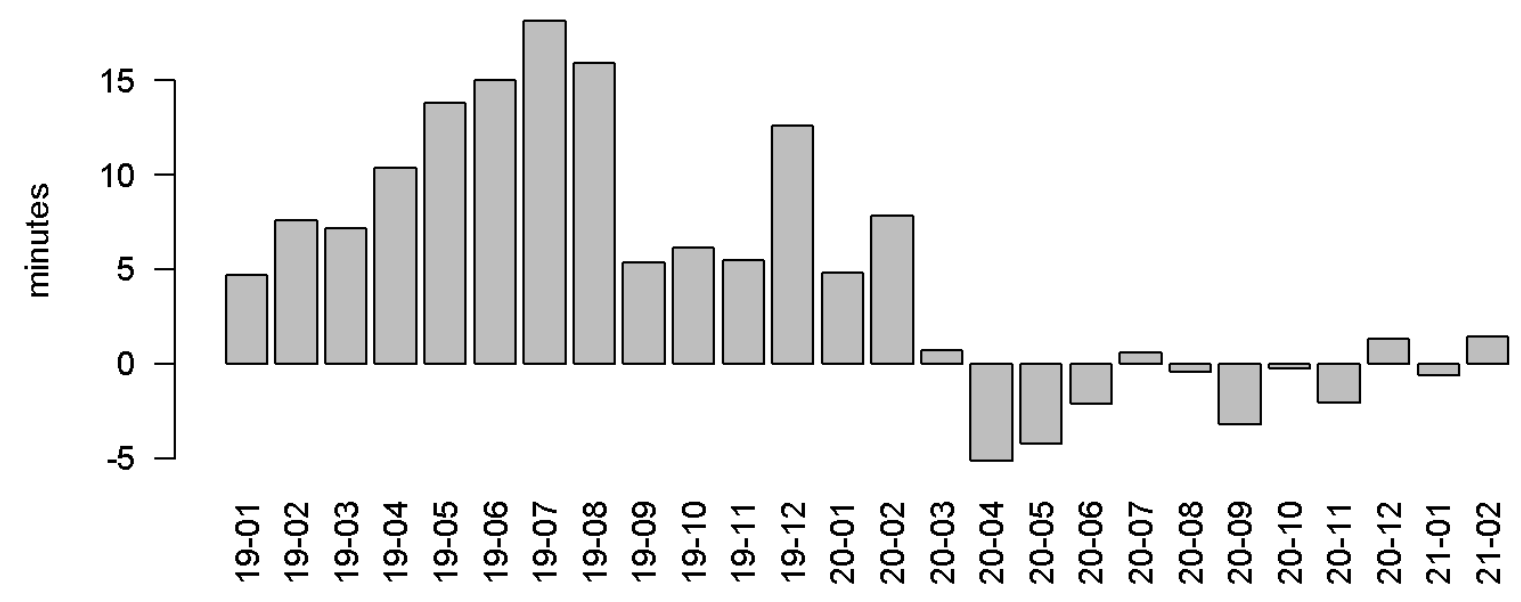

Figure 1. The bar plot displays the average departure delay time January 2019 to February 2021. The y-axis displays the average delay time in minutes, while the $\mathrm{x}$-axis displays the months.

For the year of 2019, flight delays varied from 4.7 to 18.1 minutes on average. The delay time in 2019 peaked in July and bottomed in September. There was an upward trend in delay time from January to August 2019. However, starting from September, the average delay time sharply dropped to approximately 5 minutes on average again, with a sudden spike to 12.6 minutes in December. During the entirety of 2019, Covid-19 had not yet affected the United States. The month-by-month variation in the departure delay time in 2019 is a baseline to compare with the year of 2020, when Covid-19 greatly affected the aviation industry.

The departure delay time in 2019 shows normal seasonal variations. The sudden drop in average delay time during September 2019 can be explained by passenger decrease. In July, schools hold summer break, and thus many students and families take this opportunity to undertake leisurely activities, such as travelling. With more air flight passengers, the departure delay time is most likely to increase due to longer lines, and longer turnaround times. Longer lines often lead to a slower boarding process as it takes longer for a large number of people to get on the airplane, and therefore the airplane sits at the gate longer (i.e., longer turnaround time). By September, many schools had resumed session, which caused a considerable decrease in passenger amount, and led to less delay time.

Covid-19 entered the United States in January 2020. However, the average delay time during January and February 2020 almost did not change compared with the same months in 2021 (4.8 min. vs. 4.7 min for January; 7.8 min. vs. 7.6 min. for February). Starting from March 2021, the average delay time dropped significantly. The delay time even dropped to the negative level for the majority of the months during 2020. These months include April, May, June, August, September, October, and November.

Although Covid-19 first entered the United States in January 2020, it was not officially declared a pandemic by the World Health Organization until March 2020, two months after. This may explain why Covid-19 did not have much of an effect on flight departure delay time at Philadelphia International Airport until March 2020. People were still normally travelling during the first two months of 2020, before Covid-19 was declared a pandemic. It can be further hypothesized that it was only after the World Health Organization declared Covid-19 a pandemic that people started to stay home, which caused a massive drop in airplane passengers, and in turn caused a decrease in average delay time.

Another factor that stems from a decrease in the number of passengers which affects average delay time is the number of departure flights. Less departures mean less traffic, which allows for a greater possibility of an aircraft 
leaving the gate and taxing to the runway and departing faster. Therefore, a new hypothesis is that less passengers lead to less flights, which in turn leads to lower delay time.

Table 2 and Figure 2 show the total number of departures per month from January 2019 to February 2021. Starting from April 2020, there was a drastic decrease in the number of departures. This was reflected in average delay time as well, as starting from April 2020, Philadelphia International Airport experienced some of the lowest delay time from 2019 to 2021. May 2020 held the least departure flights out of all 26 months, at a record low of 2620. May 2020 also held the second lowest delay time average at -4.2 minutes. Another example of the number of departure flights affecting delay time is July 2019. July 2019 held one of the highest numbers of departure flights, at 10,275; and it also held the highest average delay time at 18.1 minutes.

Table 2. Total number of departures from January 2019 to February 2021.

\begin{tabular}{|l|l|l|l|l|l|l|l|l|l|l|l|l|}
\hline & Jan. & Feb. & Mar. & Apr. & May & Jun. & Jul. & Aug. & Sep. & Oct. & Nov. & Dec. \\
\hline 2019 & 8899 & 8143 & 9511 & 9556 & 10452 & 10055 & 10275 & 10613 & 9688 & 10218 & 9644 & 9612 \\
\hline 2020 & 8775 & 8356 & 7911 & 3286 & 2620 & 2905 & 6062 & 6577 & 4562 & 4927 & 5471 & 5423 \\
\hline 2021 & 4731 & 3983 & \multicolumn{1}{|l|}{} \\
\hline
\end{tabular}

\section{total departures}

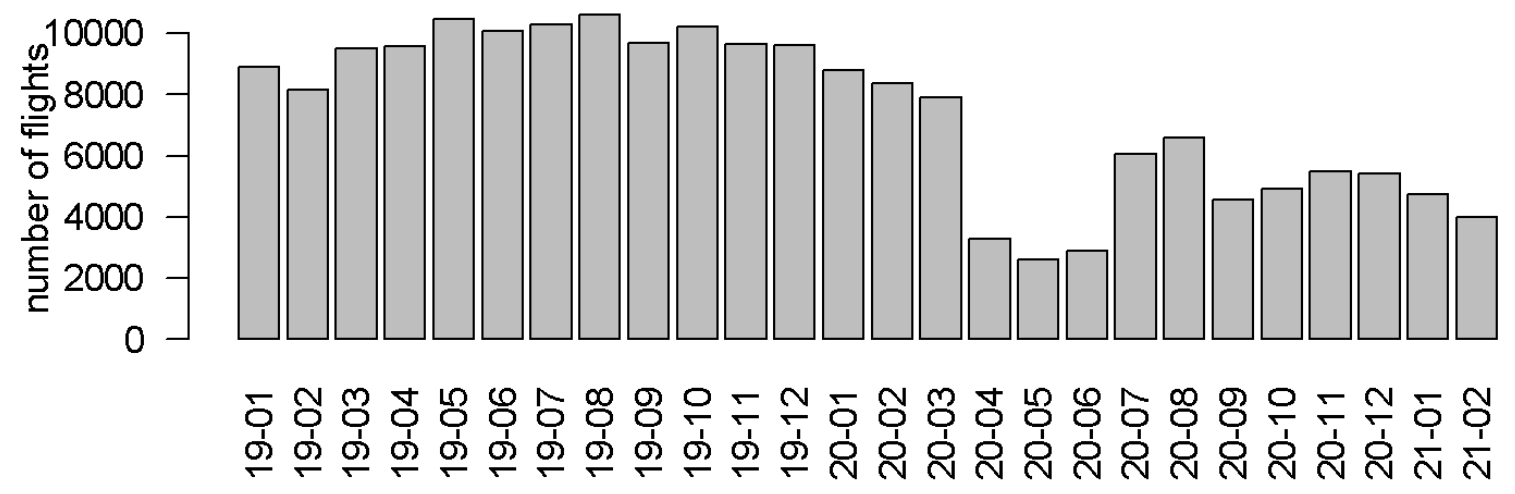

Figure 2. This bar plot shows the total number of scheduled departures per month from Philadelphia International Airport from January 2019 to February 2021. The y-axis is the number of flights, while the x-axis shows the months.

Figure 3 compares the average delay time and total number of departures. We can see a clear correlation between them. Pearson's $r$ test was used to quantify the correlation between the two variables. The result is $r=0.869$, showing that they are highly correlated with each other: the lower the number of departures, the lower the departure delay time. 


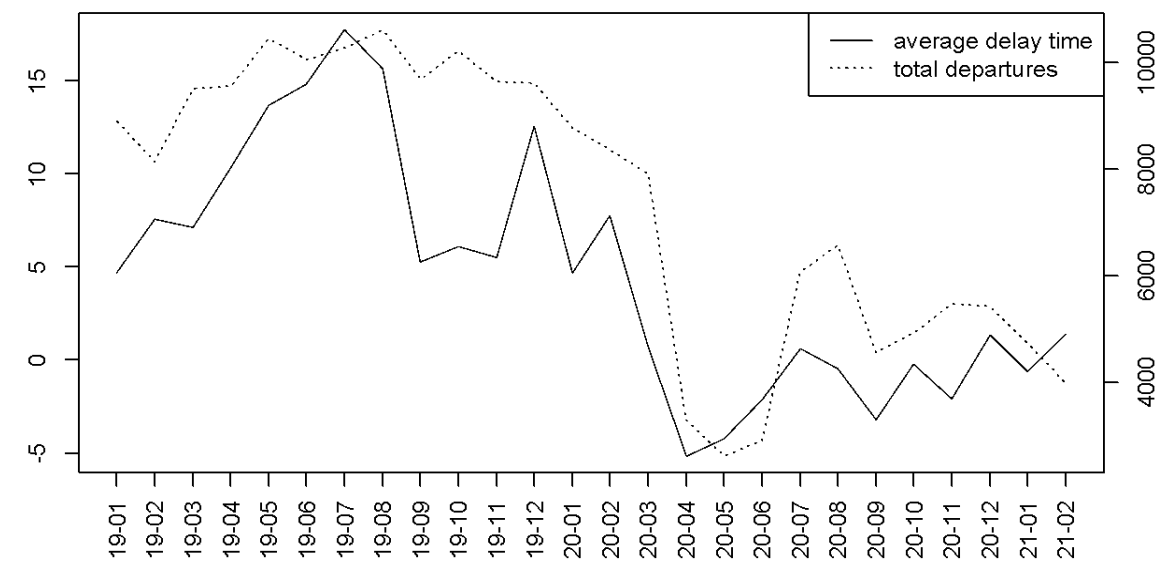

Figure 3. The average delay time (in minutes) and total number of departure flights for each month from January 2019 to February 2021. The x-axis shows the months.

There are some discrepancies with this hypothesis. For example, September 2019 held one of the highest numbers of departure flights, yet a relatively low average delay time. When compared to August 2019, this discrepancy is even more transparent. Both August and September 2019 had around 10,000 departure flights (10613 for August vs. 9688 for September), however, the average delay time in August 2019 was about 10 minutes longer compared to September 2019 (15.9 minutes for August vs. 5.3 minutes for September). This suggests that there are other factors besides the number of departure flights affecting the departure delay time.

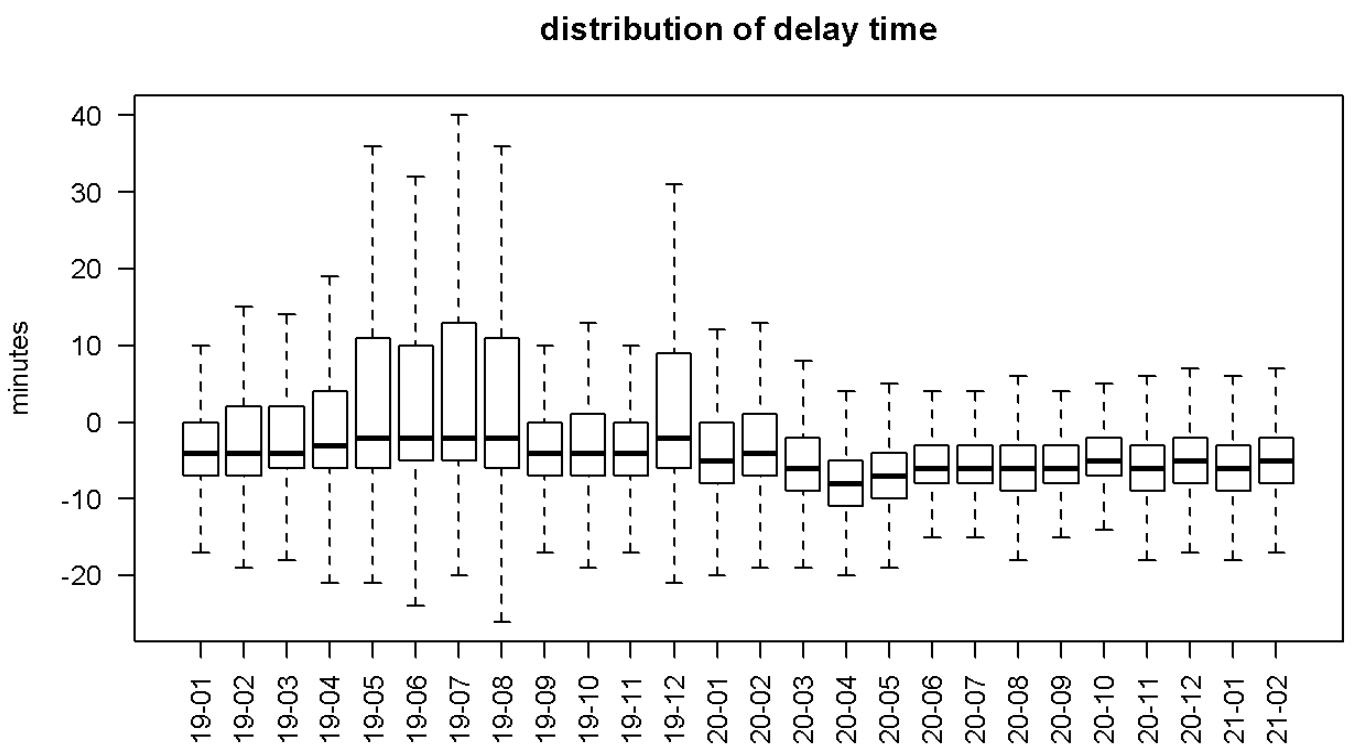

Figure 4. The boxplots show the distribution of delay time for every month. The thick black line within the boxes represents the median delay time, while the edges of the boxes represent the lower and upper quartiles of the delay time. The extreme delay times are represented by the end ticks that stretch far away from the boxes. The y-axis of the plot represents delay time in minutes, while the $\mathrm{x}$-axis represents the months. 
From the boxplots in Figure 4, which show the distribution of delay time for every month, interestingly, the median delay times among the months varied much smaller, compared to the mean delay time. The median delay times from January 2019 to February 2021 were (in minute): -4, -4, -4, -3, -2, -2, -2, -2, -4, -4, -4, -2, -5, -4, -6, -8, -7, $-6,-6,-6,-6,-5,-6,-5,-6,-5$. It is the extreme delay time that varies greatly among the months. For example, the extreme delay time July 2019 reached 40 minutes, which contributed to its highest average delay time. Even more so, the upper quartile of the delay time in July 2019 was also the highest. This means that when compared to other months, July 2019 not only had the highest extreme delay time, but also the greatest number of flights delayed by a significant amount of time. The boxplots can also explain why September 2019 saw a sudden drop in average delay time compared to August 2019, even though both months had about the same number of departure flights. Not only was September 2019's extreme delay time lower than August's by almost 30 minutes, but the upper quartile was also lower by 10 minutes. This means that overall, September had substantially less delayed flights, and the flights were delayed by less time when compared to delayed flights in August.

By compiling all the data and information from the charts together, a conclusion on how the Covid-19 outbreak affects departure delays from Philadelphia International Airport can be drawn. Overall, Covid-19 has reduced the average departure delay time at Philadelphia International Airport. There is a long cause and effect chain that ultimately reduces the delay time. Covid-19 severely reduces the number of passengers, which in turn forces airlines to cut flights. Less passengers and less flights lead to less delay time, as there are shorter lines and lesser turnaround times, combined with less traffic which allows airplanes to reach the runway earlier and depart quicker. Less flights also lead to less extreme delays, contributing to the ultimate effect of reducing average delay time.

\section{Cancellations}

Table 3: The number of flight cancellations from January 2019 to February 2021.

\begin{tabular}{|l|l|l|l|l|l|l|l|l|l|l|l|l|}
\hline & Jan. & Feb. & Mar. & Apr. & May & Jun. & Jul. & Aug. & Sep. & Oct. & Nov. & Dec. \\
\hline 2019 & 188 & 223 & 199 & 196 & 274 & 305 & 496 & 295 & 146 & 62 & 30 & 71 \\
\hline 2020 & 64 & 57 & 1576 & 2313 & 35 & 1 & 59 & 69 & 5 & 2 & 16 & 38 \\
\hline 2021 & 42 & 204 & \multicolumn{19}{|l|}{} \\
\hline
\end{tabular}

\section{cancellations}

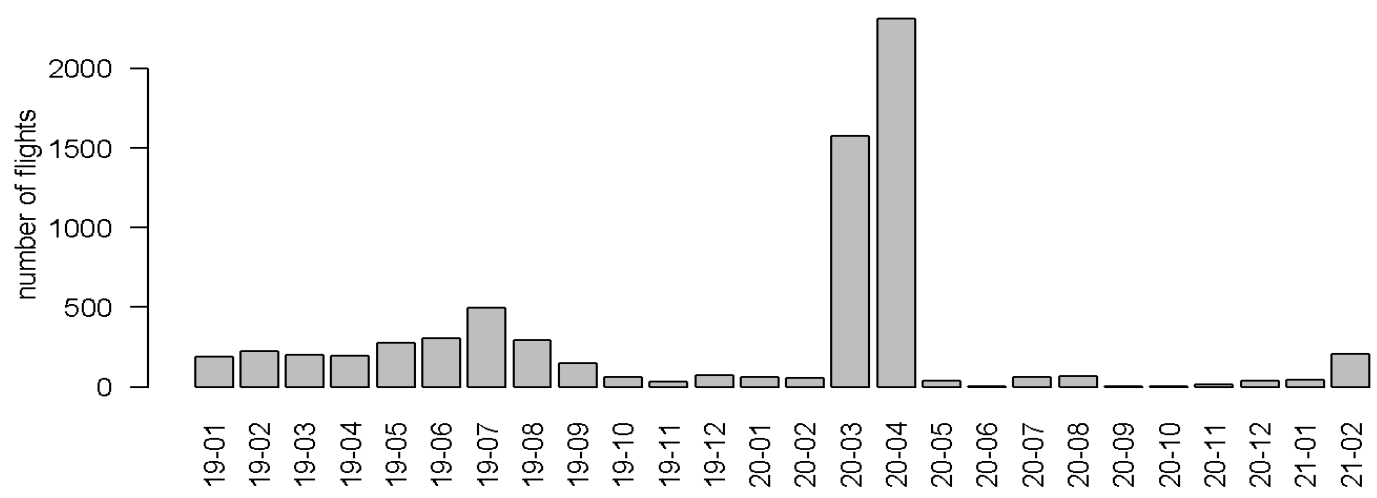

Figure 5. This bar plot shows the number of cancellations per month from Philadelphia International Airport. The yaxis represents the number of cancellations, while the $\mathrm{x}$-axis represents the months. 
Table 3 and Figure 5 show the number of departure flight cancellations at PHL from January 2019 to February. Prior to the Covid-19 outbreak, the number of cancellations remained less than 500, with a sudden increase in cancellations in July 2019 and a decrease in cancellations from September to December. In January and February 2020, the number of cancellations was reduced to a third when compared to January and February 2019. March and April 2020 showed extreme differences, as the number of cancellations jumped up to 1576 and 2313 respectively. Right after April, the number of cancellations per month plummeted down to 35 in May, and only one flight was cancelled in June 2020. The pattern of low number of cancellations (less than 100 per month) continued until February 2021, when the number of cancellations increased to over 200, paralleling the number of cancellations in February 2019.

The extreme fluctuations of the number of cancellations indicate how the airlines were trying to adjust to the situation and passenger loss caused by the pandemic. With the WHO officially declaring Covid-19 as a pandemic in March, travel restrictions were placed, and many people canceled travel plans due to fear of the virus. This caused the number of flight cancellations to shoot up during March and April, as there were many empty or near empty flights which forced airlines to cancel many routes. The sudden decline in the number of cancellations in May and throughout the rest of the season can be explained by the much lower number of scheduled flights, which was previously expounded upon.

\section{Conclusions and Discussion}

The Covid-19 outbreak greatly affected flight delay time and cancellations at Philadelphia International Airport. The average departure delay time dropped tremendously, and it dipped into the negative level for the first time since January 2019. The study found that departure delay time is highly correlated with the number of flights: the lower the number of flights, the lower the delay time. The decrease in the number of flights led to less extreme delays, which lowered the average delay time while the median delay time was less affected. The ultimate cause is the lack of passengers, as the number of passengers dictates the number of flights an airline can successfully operate. Flight cancellations sharply rose in March and April 2020, and then quickly dropped to lower than the pre-pandemic level. This shows how the airlines were trying to adjust to the situation and passenger loss caused by the pandemic.

There were some limitations during the course of this research. Although it was stated that since Covid-19 less passengers travelled on airplanes, data on the number of passengers departing from Philadelphia International Airport was not found. As a result, assumptions had to be made, such as the decrease in delay time in September 2019 was caused by schools opening and less people flying. Data on passenger amounts, if found, could either solidify the argument or weaken it. Furthermore, causes for departure delays were not taken into account. For example, airplanes can run into problems that are independent of Covid-19, such as aircraft mechanical issues. Other factors such as regulations on airport security check may also affect the departure delay time.

Flight on-time accountability is very important. Future research should include more data points, including other airports and longer time periods in order to solidify the argument. For example, airports in New York, Chicago, Atlanta, and San Francisco should be examined due to their importance to the economy and air travel in the United States. Examining the aforementioned topics will give an even clearer insight into the magnitude in which the Covid19 pandemic affected air traffic in the United States.

\section{Acknowledgements}

The author would like to thank Mr. Brian Vernachio for his advice and help on this project. 


\section{References}

Abdelghany, K. F., S. Shah, S., Raina, S., \& Abdelghany, A. F. (2004). A model for projecting flight delays during irregular operation conditions. Journal of Air Transport Management, 10(6), 385-394. https://doi.org/10.1016/j.jairtraman.2004.06.008

Amankwah-Amoah, J. (2020). Note: Mayday, Mayday, Mayday! Responding to environmental shocks: Insights on global airlines' responses to COVID-19. Transportation Research Part E: Logistics and Transportation Review, 143, 102098. https://doi.org/10.1016/j.tre.2020.102098

Asfe, M. K., Zehi, M. J., Shahiki Tash, M. N., \& Yaghoubi, N. M. (2014). Ranking different factors influencing flight delay. Management Science Letters, 4(7), 1397-1400. https://doi.org/10.5267/j.ms1.2014.6.030

Bailey, J. (2020, June 10). American Airlines Set To Reactivate 140+ Narrowbody Aircraft. Simple Flying. https://simpleflying.com/american-airlines-narrowbody-reactivation/.

Ball, M., Barnhart, C., Dresner, M., Hansen, M., Neels, K., Odoni, A., Peterson, E., Sherry , L., Trani, A., \& Zhu, B. (2010). Total Delay Impact Study: A Comprehensive Assessment of the Costs and Impacts of Flight Delay in the United States. National Center of Excellence for Aviation Operations Research.

Barnett, A. (2020). Covid-19 Risk Among Airline Passengers: Should the Middle Seat Stay Empty? MedRxiv. https://doi.org/10.1101/2020.07.02.20143826

Budd, L., Ison, S., \& Adrienne, N. (2020). European airline response to the COVID-19 pandemic - Contraction, consolidation and future considerations for airline business and management. Research in Transportation Business \& Management, 37, 100578. https://doi.org/10.1016/j.rtbm.2020.100578

Carvalho, L., Sternberg, A., Maia Gonçalves, L., Beatriz Cruz, A., Soares, J. A., Brandão, D., Carvalho, D., \& Ogasawara, E. (2020). On the relevance of data science for flight delay research: a systematic review. Transport Reviews, 1-30. https://doi.org/10.1080/01441647.2020.1861123

Forsyth, P., Guiomard, C., \& Niemeier, H.-M. (2020). Covid -19, the collapse in passenger demand and airport charges. Journal of Air Transport Management, 89, 101932. https://doi.org/10.1016/j.jairtraman.2020.101932

Hsu, C. I., Hsu, C. C., \& Li, H. C. (2007). Flight-delay propagation, allowing for behavioural response. International Journal of Critical Infrastructures, 3(3), 301-326. https://doi.org/10.1504/ijcis.2007.014113

Lamb, T. L., Winter, S. R., Rice, S., Ruskin, K. J., \& Vaughn, A. (2020). Factors that predict passengers willingness to fly during and after the COVID-19 pandemic. Journal of Air Transport Management, 89, 101897. https://doi.org/10.1016/j.jairtraman.2020.101897

Pallini, T. (2021, January 17). The pandemic devastated airlines in 2020 and forced many out of business - here's the most notable that didn't make it to 2021. Business Insider. https://www.businessinsider.com/airlines-thatwent-out-of-business-in-2020-2021-1.

Pongpirul, K., Kaewpoungngam, K., Chotirosniramit, K., \& Theprugsa, S. (2020). Commercial airline protocol during COVID-19 pandemic: An experience of Thai Airways International. PLOS ONE, 15(8). https://doi.org/10.1371/journal.pone.0237299

Serrano, F., \& Kazda, A. (2020). The future of airports post COVID-19. Journal of Air Transport Management, 89, 101900. https://doi.org/10.1016/j.jairtraman.2020.101900

Suau-Sanchez, P., Voltes-Dorta, A., \& Cugueró-Escofet, N. (2020). An early assessment of the impact of COVID19 on air transport: Just another crisis or the end of aviation as we know it? Journal of Transport Geography, 86, 102749. https://doi.org/10.1016/j.jtrangeo.2020.102749

Sun, X., Wandelt, S., \& Zhang, A. (2020). How did COVID-19 impact air transportation? A first peek through the lens of complex networks. Journal of Air Transport Management, 89, 101928. https://doi.org/10.1016/j.jairtraman.2020.101928

Wang, P. T., Schaefer, L. A., \& Wojcik, L. A. (2003). Flight connections and their impacts on delay propagation. 22nd Digital Avionics Systems Conference Proceedings (Cat No 03CH37449) DASC-03, 1. https://doi.org/10.1109/dasc.2003.1245858 